\title{
Reduction of Low-grade Manganese Dioxide Ore Pellets by Biomass Wheat Stalk
}

\author{
Honglei $Z H A N G^{1)}$, Guocai ZHU' ${ }^{2) \dagger}$, Hong $Y A N^{1)}$, Yuna $Z H A O^{2)}$, Tiancheng $L I^{2)}$ and \\ Xiujuan FENG ${ }^{2}$ \\ 1) College of Life Science and Bio-engineering, Beijing University of Technology, Beijing 100124, China \\ 2) Institute of Nuclear and New Energy Technology, Tsinghua University, Beijing 102201, China \\ [Manuscript received 10 December 2012, in revised form 13 January 2013] \\ (c) The Chinese Society for Metals and Springer-Verlag Berlin Heidelberg
}

\begin{abstract}
An investigation on reducing low-grade manganese dioxide ore pellets was carried out by using wheat stalk as reductant. The main impact factors of reduction percent such as particle size, biomass/ore ratio, heating rate, nitrogen flow rate, temperature and time in reduction process were discussed. The morphology and component of manganese dioxide ore particle at different stages were also analyzed by scanning electron microscopy (SEM) and energy dispersive X-ray spectroscopy (EDS). The results show the increase of the reduction temperature and time, biomass/ore ratio, and the decrease of particle size, heating rate and nitrogen flow rate can significantly enhance reduction efficiency. The reduction kinetic of the manganese ore is controlled by three-dimensional mass diffusion of gaseous reductive volatiles passing from the surface to the core of the ore particles. The activation energy $E$ and frequency factor $A$ were calculated to be $24.15 \mathrm{~kJ} \cdot \mathrm{mol}^{-1}$ and $166 \mathrm{~min}^{-1}$, respectively. Biomass pyrolysis volatiles adsorbed onto the surface of the ore particle leads to serious variation of the microstructures and chemical composition of the manganese ore particles.
\end{abstract}

KEY WORDS: Biomass; Reduction; Manganese oxide ore; Kinetics

\section{Introduction}

For the vigorous growing demand of steel industry, carbon-zinc battery, dietary additives, fertilizers, and dyes industries, high-grade manganese ores are exhausted step by step in China, thus, much attentions have been drawn to recover manganese from low-grade manganese dioxide ores in recent years ${ }^{[1-3]}$. Due to the manganese only can be extracted by sulfuric acid from the reduced manganese dioxide ores, coal roasting reduction followed by acid leaching technology is extensively applied to produce electrolytic manganese, but unfortunately, it causes serious problems including high consumption of energy, emission of smoke dust and gaseous pollutants ${ }^{[4-6]}$. Thus, many direct reductive acid leaching technologies have

\footnotetext{
† Corresponding author. Prof., Ph.D.; Tel: $\quad+8610$ 89796081; Fax: +86 10 69771464; E-mail address: zhugc@mail.tsinghua.edu.cn (Guocai ZHU).
}

DOI: $10.1007 / \mathrm{s} 40195-012-0250-\mathrm{x}$ been developed to treat low-grade manganese oxide ore by using a variety of reducing agents, such as molasses ${ }^{[7]}, \mathrm{SO}_{2}^{[8]}$, oxalic acid ${ }^{[9]}$, thiosulfate ${ }^{[10]}$ and iron ${ }^{[11]}$. However, complicated downstream purification process and serious water pollution makes these leaching processes difficult for industrial application $^{[12]}$.

Nowadays, biomass wastes, such as sawdust, straw, wheat straw, cornstalk and bamboo, have been considered as environment-friend and low-cost reducing agents for roasting reduction of manganese dioxide ores ${ }^{[13]}$. Sawdust, cornstalk and straw as reducing agents have been investigated by our research members Cheng et al. ${ }^{[14]}$, Song et al. ${ }^{[15]}$ and Zhao et al. ${ }^{[16]}$ respectively, and the results showed that over $90 \%$ leaching recovery of the manganese was achieved under the optimal experimental conditions: sawdust/ore mass ratio of $1: 5$, roasting at $500{ }^{\circ} \mathrm{C}$ for $40 \mathrm{~min}$, dilute sulfuric acid as leaching acid, $\mathrm{H}_{2} \mathrm{SO}_{4}$ concentration of $1 \mathrm{~mol} \cdot \mathrm{L}^{-1}$, liquid/solid ratio of $10: 1$ and leaching at $60{ }^{\circ} \mathrm{C}$ for $40 \mathrm{~min}$. A further investigation showed 
that the powder-grade manganese dioxide ore could be totally reduced with biomass/ore ratio at 1:10 under nitrogen atmosphere, and the reaction followed an independent parallel first-order reaction kinetic model ${ }^{[16]}$. The mechanism considered was that under inert atmosphere biomass thermally decomposed to over fifty kinds of heavy volatiles (constituted of alkanes, aromatic hydrocarbons, alcohols, ethers, aldehydes, ketones and carboxylic acids) and noncondensable gases $\left(\mathrm{H}_{2}, \mathrm{CO}, \mathrm{CH}_{4}, \mathrm{C}_{2} \mathrm{H}_{6}, \mathrm{C}_{2} \mathrm{H}_{2}\right.$ and $\mathrm{C}_{2} \mathrm{H}_{4}$ ) which were direct reductants to reduce manganese dioxide ore.

Moreover, our research group recently had successfully established an industrial production line with annual output of $1 \times 10^{5}$ tons of powder-grade manganese monoxide ore by adopting the biomass reduction technology in Guangxi, China, which further demonstrated that this technology was prospective and effective for large-scale industrial application to treat low-grade manganese dioxide ores in future. However, it was also found that low-density manganese ores dust could be easily diffused during the process of raw materials mixing, desiccating, reduction roasting and product cooling in rotary kiln, which could lead to serious environmental problem if without efficient dust-removal system. The alternative settlement to reduce the emission of the dust was using large size ore pellets to substitute ore powder as raw material for industrial production. Due to manganese ore pellets is of higher density, it is necessary and significant to investigate the impact factors such as particle size, biomass/ore ratio, temperature, time, heating rate, nitrogen flow rate and reaction kinetics for better understanding of influence of particle morphology change on the reduction process.

\section{Experimental}

\subsection{Raw materials}

The samples of wheat stalk, from Beijing, China, are grounded to fine powder and the fraction with particle size lower than $200 \mu \mathrm{m}$ was chosen for the experiments. The ultimate and proximate analysis was given in Table 1.

Low-grade manganese dioxide ores, collected from Guangxi, China, contained 19.07 wt.\% Mn, 13.00 wt.\% Fe, 14.64 wt.\% Si, 1.20 wt.\% Ca, 0.30 wt.\% $\mathrm{Mg}, 0.16$ wt. $\% \mathrm{Ni}$ and 0.03 wt.\% Co. The ores were crushed, dry-sieved into different size fractions and the manganese and iron contents in different fractions were presented in Table 2 .

\subsection{Experimental procedure}

The reduction experiments were carried out in a sealed tubular furnace. The calculated amount of manganese ore and biomass were weighed and mixed through in a $100 \mathrm{~mL}$ crucible, then put into a quartz vessel and calcined to a certain temperature with a predetermined heating rate. Before the reduction roasting, the reactor was purged with nitrogen $30 \mathrm{~min}$ at $2 \mathrm{~L} \cdot \mathrm{min}^{-1}$ to establish the airless environment. At regular time interval, the reduced ore samples were quickly transferred to a beaker containing $100 \mathrm{~mL}$ leach solution (the concentration of sulfuric acid was $1 \mathrm{~mol} \cdot \mathrm{L}^{-1}$ ) and then agitated continuously at $90{ }^{\circ} \mathrm{C}$ for $1 \mathrm{~h}$ with a stirring rate of $400 \mathrm{r} / \mathrm{min}$. Then the leaching solution was filtered and the filtrate was analyzed for calculating manganese recovery $\left(W_{\mathrm{r}}\right)$ by perchloric acid oxidation-ferrous ammonium sulfate titration analysis as described in Eq. (1). The microstructure and semi-quantitative chemical analysis of the roasted ore pellets was determined by Tescan KYKY-EM 3900M SEM and EDS.

$$
W_{\mathrm{r}}=M m_{0} V V_{1} / m V_{2}
$$

where $m$ is the manganese weight in manganese ore sample $(\mathrm{g}) ; m_{0}$ is the molecular weight of manganese $(\mathrm{g} / \mathrm{mol}) ; M$ is the concentration of ferrous ammonium sulfate solution $(\mathrm{mol} / \mathrm{L}) ; V$ is the consumed volume of ferrous ammonium sulfate solution $(\mathrm{L}) ; V_{1}$ is the volume of total filtrate $(\mathrm{mL}) ; V_{2}$ is the volume of filtrate for analysis $(\mathrm{mL})$.

Table 1 The ultimate and proximate analysis of the biomass samples (wt. \%)

\begin{tabular}{ccccc}
\hline Element analysis & $\mathrm{C}$ & $\mathrm{O}$ & $\mathrm{H}$ & $\mathrm{N}$ \\
\hline & 42.13 & 43.18 & 4.05 & 1.04 \\
Proximate analysis & Moisture & Volatiles & Fixed carbon & Ash \\
& 8.01 & 80.10 & 15.13 & 4.89 \\
\hline
\end{tabular}

Table 2 Chemical composition of Guangxi manganese oxide ore of different size fractions

\begin{tabular}{ccccccc}
\hline Size fraction (mm) & $0.85-2.00$ & $0.43-0.85$ & $0.25-0.43$ & $0.18-0.25$ & $0.15-0.18$ & $<0.15$ \\
\hline Mn (wt.\%) & 24.38 & 23.67 & 19.61 & 18.20 & 14.83 & 11.13 \\
Fe (wt.\%) & 15.26 & 15.01 & 13.57 & 12.73 & 11.47 & 9.34 \\
\hline
\end{tabular}




\section{Results and Discussion}

\subsection{Biomass pyrolysis experiments}

\subsubsection{Effect of the original ore particle size}

Effect of the original ore particle size on roasting reduction was investigated by varying its size fractions from $0.85-2.00 \mathrm{~mm}$ to $<0.15 \mathrm{~mm}$. The experimental condition is that reaction time is $30 \mathrm{~min}$, reduction temperature is $550{ }^{\circ} \mathrm{C}$, biomass/manganese ore mass ratio is $1: 10$, heating rate is $40{ }^{\circ} \mathrm{C} \cdot \mathrm{min}^{-1}$, and nitrogen flow rate is $0 \mathrm{~L} / \mathrm{min}$. As presented in Fig. 1 , the results show that the reduction rate of manganese dioxide ore dramatically increases from $58.70 \%$ to $98.96 \%$ with the decrease of the particle size from $0.85-2.00 \mathrm{~mm}$ to $0.25-0.43 \mathrm{~mm}$. The higher reduction rate for smaller-size particles is caused by the increased contact area of manganese ore and reductive gases released from biomass thermal decomposition. With ore size fractions of less than $0.43 \mathrm{~mm}$, almost $100 \%$ reduction percent can be obtained, which is much higher than the reduction rate of industrial requirement (90\%). However, in order to get sufficient experimental status a relatively larger particle size of 0.43-0.85 $\mathrm{mm}$ was used for the following reduction trials.

\subsubsection{Effect of biomass/ore ratio}

To study the effect of the biomass/ore ratio on the reduction rate, experiments were performed at $550{ }^{\circ} \mathrm{C}$ with the reaction time of $30 \mathrm{~min}$, heating rate of $40{ }^{\circ} \mathrm{C} \cdot \mathrm{min}^{-1}$, particle size of $0.43-0.85 \mathrm{~mm}$ and nitrogen flow rate of $0 \mathrm{~L} \cdot \mathrm{min}^{-1}$, while the mass ratio of biomass to ore was changed from 0.25:10 to 2.0:10. The results are presented in Fig. 2. It can be observed that a general increase in the reduction rate of the manganese ore takes place along with biomass/ore ratio increasing. The increase of the biomass/ore ratio in fact leads to more reducing substances generated from wheat stalk which causes higher manganese extraction. It is found that under the above condition the reduction efficiency is more than $90 \%$ only when the biomass/ore ratio increases to $1.5: 10$.

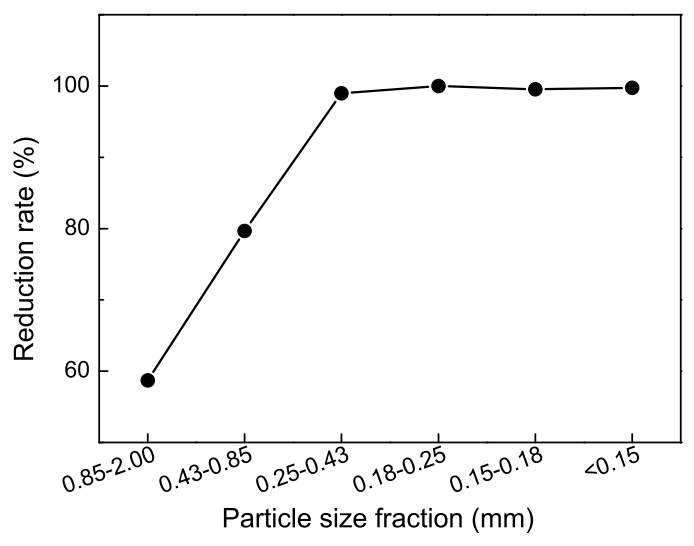

Fig. 1 Effect of the ore particle size on the reduction rate of the manganese oxide ore pellets

\subsubsection{Effect of the heating rate}

Under the conditions of the roasting temperature of $550{ }^{\circ} \mathrm{C}$, reaction time of $30 \mathrm{~min}$, mass ratio of biomass to ore of $1.0: 10$, particle size of $0.43-0.85$ $\mathrm{mm}$ and nitrogen flow rate of $0 \mathrm{~L} \cdot \mathrm{min}^{-1}$, the influence of heating rate on the reduction degree of the manganese ore was investigated. As shown in Fig. 3 , the results illustrate that the reduction rate of the manganese ore strongly depends on the heating rate. The increase of reduction rate from $79.80 \%$ to $94.75 \%$ is obtained with the decrease of the heating rate from $40{ }^{\circ} \mathrm{C} \cdot \mathrm{min}^{-1}$ to $5^{\circ} \mathrm{C} \cdot \mathrm{min}^{-1}$, which can be related to the instability characteristic of the organic volatiles generated from biomass decomposition. The biomass is decomposed rapidly with high heating rate, and the reduction reaction efficiency is much lower than release rate of the biomass volatiles at high heating rate, thus a great deal of unreacted volatiles involve further thermal decomposition. With low heating rate the biomass volatiles release relatively slower, the reductant gas can efficiently involve the reduction process. Therefore, when the heating rate is $5^{\circ} \mathrm{C} \cdot \mathrm{min}^{-1}$, the manganese ore with particle size of $<0.85 \mathrm{~mm}$ and biomass/ore ratio of 1.0:10 can be used for industrial production to reduce toxic dust release.

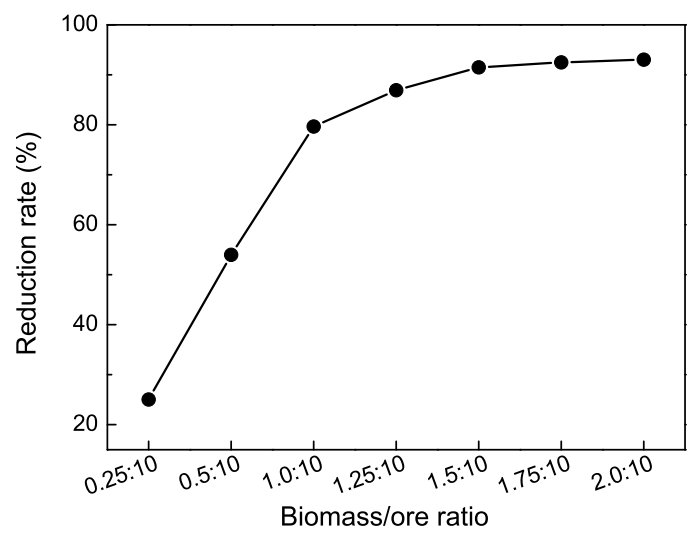

Fig. 2 Effect of the biomass/ore ratio on the reduction rate of the manganese oxide ore pellets

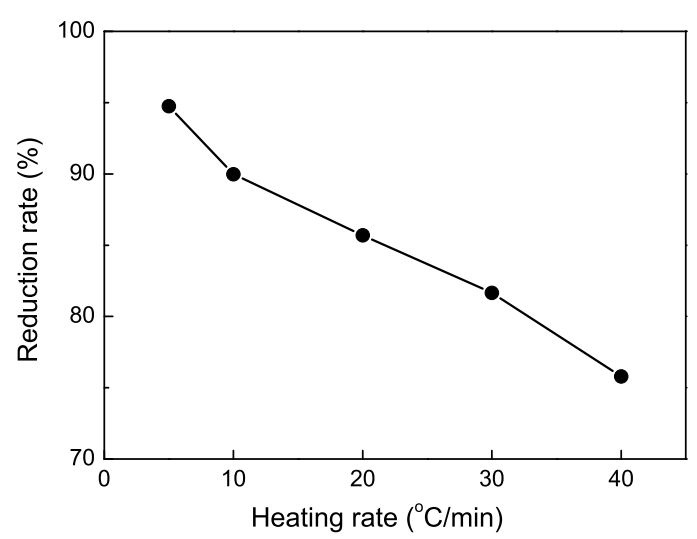

Fig. 3 Effect of the heating rate on reduction rate of the manganese oxide ore pellets 


\subsubsection{Effect of the nitrogen flow rate}

The effect of the nitrogen flow rate on the reduction ratio was examined by fixing roasting temperature at $550{ }^{\circ} \mathrm{C}$, reaction time at $30 \mathrm{~min}$, mass ratio of biomass to ore at 1.0:10, the particle size at 0.43 $0.85 \mathrm{~mm}$ and the heating rate at $40^{\circ} \mathrm{C} \cdot \mathrm{min}^{-1}$, the results are shown in Fig. 4. It is clear that the increase of the nitrogen flow rate gradually lowers reduction rate, and especially when increasing nitrogen flow rate from 0 to $0.25 \mathrm{~L} \cdot \mathrm{min}^{-1}$, an obvious decline of the reduction rate from $79.80 \%$ to $65.51 \%$ is obtained. This result confirms that the biomass reduction process takes place by solid-gaseous reaction mechanism, which means that the reductive volatiles are first released from biomass thermal decomposition, then diffuse between the ore particle and react with the manganese oxide in ore in gaseous state.

\subsubsection{Effects of temperature and time}

The effects of the temperature and time on the reduction ratio were studied when the mass ratio of biomass to ore was 1.0:10, particle size was $0.43-$ $0.85 \mathrm{~mm}$, nitrogen flow rate was $0 \mathrm{~L} \cdot \mathrm{min}^{-1}$ and heating rate was $40^{\circ} \mathrm{C} \cdot \mathrm{min}^{-1}$. The results, shown in Fig. 5 , indicate that the temperature and time have significant influence on the reduction ratio of the manganese dioxide ore. When the reaction temperature is

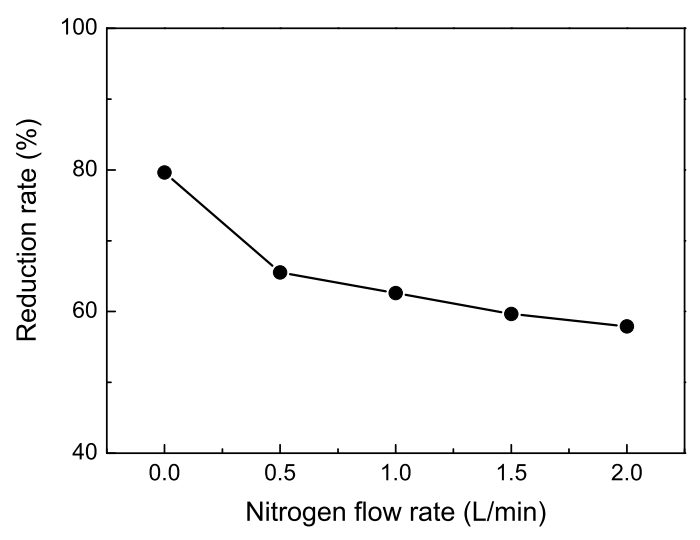

Fig. 4 Effect of the nitrogen flow rate on reduction rate of manganese oxide ore pellets

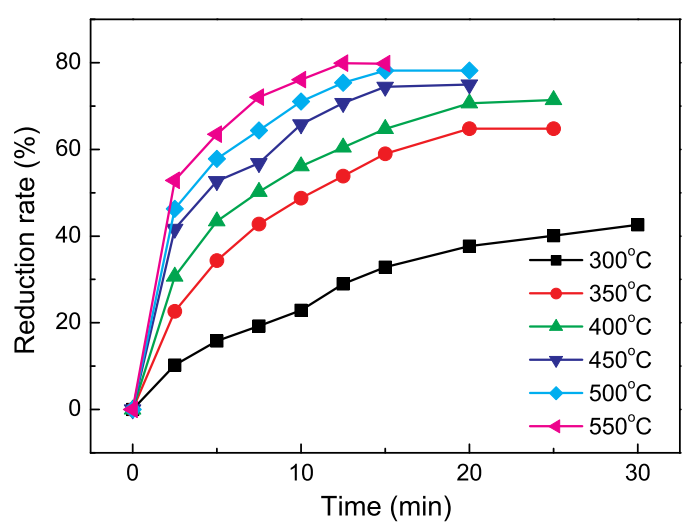

Fig. 5 Effects of the temperature and the time on reduction rate of the manganese oxide ore pellets
$300{ }^{\circ} \mathrm{C}$, the overall reduction rate steadily increases to $42.61 \%$ within $30 \mathrm{~min}$, which illustrates that the reduction process at the relative low temperature may be controlled by biomass pyrolysis process. However, within the temperature range of $350-550{ }^{\circ} \mathrm{C}$, the reduction rate first increases dramatically for $10 \mathrm{~min}$ and then levels off to a final value. Moreover, the temperature increase improves both the rate and the velocity of the reduction reaction which might be controlled by solid diffusion and (or) reduction chemical reaction.

\subsection{Kinetic analysis}

Based on above analysis of the main experimental data, the detailed mechanism of the reduction process may be followed by three basic steps: (1) biomass pyrolyzes to release reductive volatiles; (2) the volatiles are adsorbed onto the surface of the ore particles; (3) reduction reaction happens gradually from the surface to the core of ore pellets.

Due to the reduction is exothermic in nature ${ }^{[15]}$, heat transfer effect might be also important. And the surface property of larger ore pellets will cause lower adsorption rate for reactant agent onto the ore pellet surface, which may also play a certain role in determining kinetics of the heterogeneous reduction reaction $^{[17]}$.

In order to obtain kinetics rate controlling step and thermal dynamic parameters, the experimental data from $350{ }^{\circ} \mathrm{C}$ to $550{ }^{\circ} \mathrm{C}$ is correlated to different kinetic equations for gas-solid reactions ${ }^{[18]}$, such as geometrical models, diffusion models and reaction models. The following three-dimensional diffusion kinetic model is found to be fit the data best with correlation coefficient more than 0.98, as shown in Fig.2.

$$
\left[1-(1-\alpha)^{1 / 3}\right]^{2}=k t / r^{2}
$$

where $\alpha$ is the extent of conversion (dimensionless); $k$ is reaction rate constant; $t$ is reaction time ( $\mathrm{min})$; $r$ is average radius of pellet particles $(\mathrm{m})$, defined as $r=\left(r_{1} \times r_{2}\right)^{1 / 2}, r_{1}$ and $r_{2}$ are the upper and lower radius of pellet particles.

Herein, this suggests that the reduction rate of manganese oxide ore pellets by biomass is controlled by the diffusion of reductive volatiles through the "product" layer, which are composed of reduced and unreduced oxide minerals, including manganese monoxide and ferrous oxide, quartz and so on.

The reaction constant $k$ can be expressed as Arrhenius formula:

$$
\ln (k)=-E / R T+\ln (A)
$$

where $T$ is the reduction temperature $(\mathrm{K}), E$ is the activation energy $\left(\mathrm{J} \cdot \mathrm{mol}^{-1}\right), R$ is the gas constant $\left(8.314 \mathrm{~J} \cdot \mathrm{mol}^{-1} \cdot \mathrm{K}^{-1}\right), A$ is the pre-exponential or frequency factor $\left(\mathrm{min}^{-1}\right)$.

By plotting $\ln k$, from the data of Fig. 6, against $T / 1000$, the activation energy $E$ and frequency factor 
$A$ of biomass reduction of manganese oxide ore pellets can be calculated and the values are $24.15 \mathrm{~kJ} \cdot \mathrm{mol}^{-1}$ and $166 \mathrm{~min}^{-1}$, as shown in Fig. 7 .

\subsection{SEM and EDS analysis}

The variation of the microstructures and the chemical compositions for the manganese ore pellets with different sintering times at $550{ }^{\circ} \mathrm{C}$ were examined by SEM and EDS, the results are shown in Fig. 8 and Table 3 . At the reaction time of $5 \mathrm{~min}$, the biomass volatiles (black color in Fig. 8b) are adsorbed onto the surface of the ore particles, while the

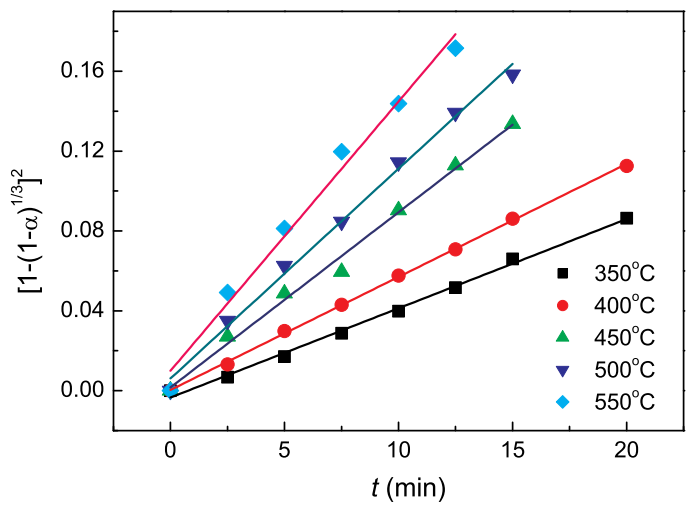

Fig. 6 Plot of $\left[1-(1-\alpha)^{1 / 3}\right]^{2}$ against $t$
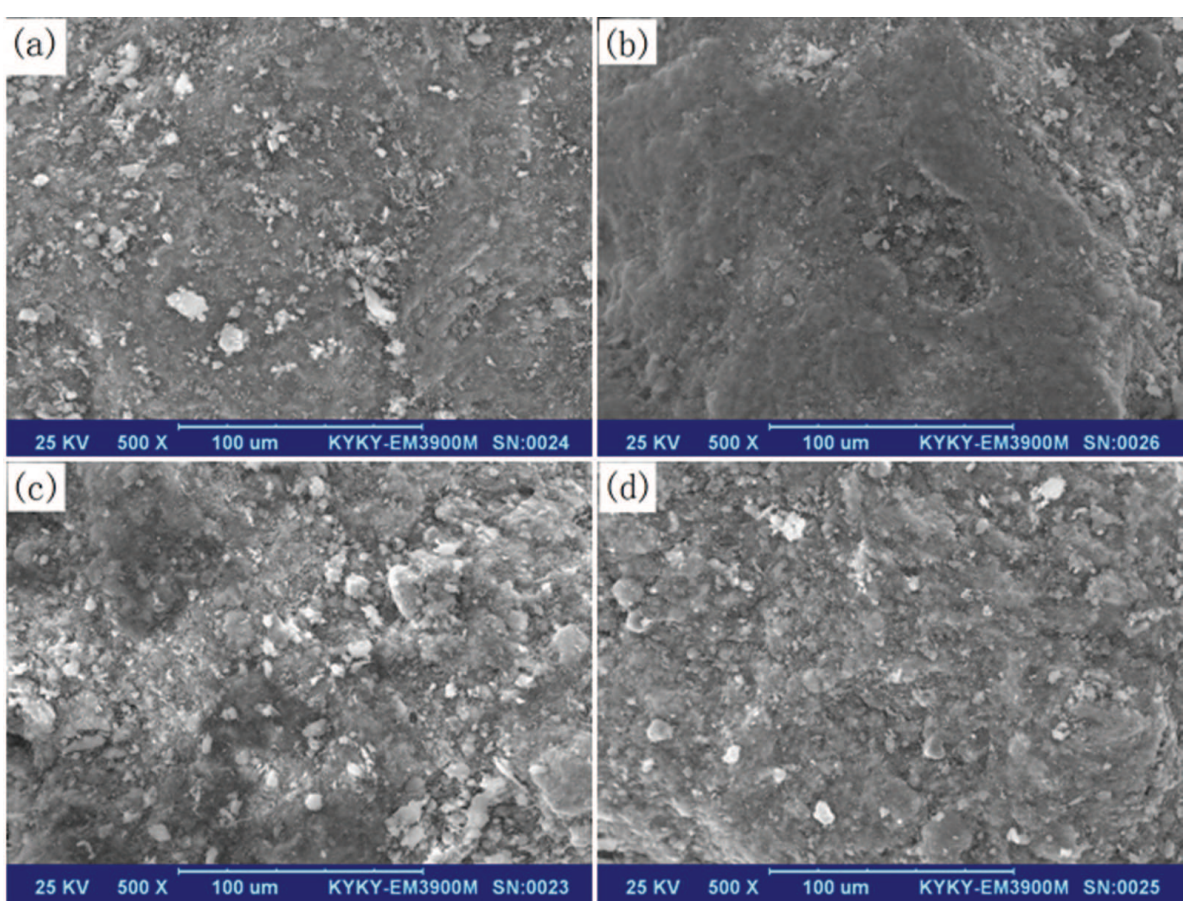

Fig. 8 SEM images of the biomass reduced manganese ore pellets at $550{ }^{\circ} \mathrm{C}$ for $0 \mathrm{~min}(\mathrm{a}), 5 \mathrm{~min}$ (b), 10 $\min (\mathrm{c})$ and $15 \min (\mathrm{d})$

Table 3 EDS results of the biomass reduced manganese ore pellets at $550{ }^{\circ} \mathrm{C}$ for different times (wt.\%)

\begin{tabular}{cccccc}
\hline Time & $\mathrm{C}$ & $\mathrm{O}$ & $\mathrm{Mn}$ & $\mathrm{Fe}$ & $\mathrm{Si}$ \\
\hline $0 \mathrm{~min}$ & 15.14 & 48.01 & 15.13 & 8.19 & 9.04 \\
$5 \mathrm{~min}$ & 30.32 & 47.20 & 7.72 & 3.18 & 7.23 \\
$10 \mathrm{~min}$ & 35.16 & 36.96 & 12.10 & 6.15 & 5.11 \\
$15 \mathrm{~min}$ & 35.44 & 35.48 & 9.86 & 6.47 & 4.40 \\
\hline
\end{tabular}

reduction reaction begins with low reaction rate, resulting in glossier surfaces of the ore pellets. Afterwards, the volatiles react with the manganese ore or further thermally degrade simultaneously, which turns the manganese ore particles rough again (Fig. $8 \mathrm{c}$ ). Many cracks on the ore surface can be seen from Fig. 8d, demonstrating that the reduction reaction happens from the surface to the core. From EDS analysis (Table 3 ), volatiles adsorption process leads to the increase of the carbon content and the decrease of oxygen content on the ore pellets surface, indicating that reduction reaction takes place.

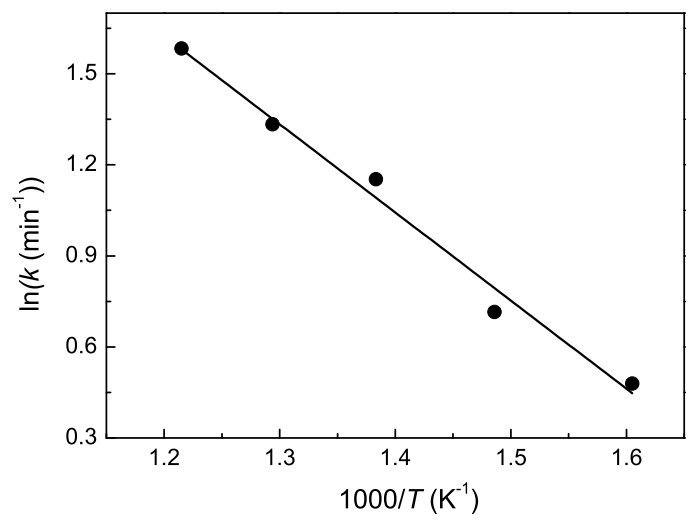

Fig. 7 Arrhenius plot for manganese ore pellets reduction by biomass 


\section{Conclusions}

In this paper, results on reduction of manganese ore pellets by biomass are presented as follow:

(1) Particle size of low-grade manganese ore, biomass/ore ratio, heating rate, nitrogen flow rate, reaction temperature and reaction time are the key parameters that control the reduction reaction process. The reduction rate is increased greatly at higher biomass/ore ratio, reaction temperature and time and lower particle size, heating rate, nitrogen flow rate. The optimal conditions for biomass reduction of the manganese ore pellets is roasting temperature of $550{ }^{\circ} \mathrm{C}$, reaction time of $15 \mathrm{~min}$, mass ratio of biomass to ore of 1.0:10, particle size of $<0.85 \mathrm{~mm}$, nitrogen flow rate of $0 \mathrm{~L} \cdot \mathrm{min}^{-1}$ and heating rate of $5^{\circ} \mathrm{C} \cdot \mathrm{min}^{-1}$.

(2) The whole reduction process can be divided into three stages as follows: biomass volatiles release, ore particle adsorption of the volatiles, reduction reaction from the surface to the core of the pellets. The rate-limiting step is reduction reaction step. The kinetic reaction follows a three-dimensional diffusion kinetic model with activation energy $\mathrm{E}$ and frequency factor $\mathrm{A}$ at $24.15 \mathrm{~kJ} \cdot \mathrm{mol}^{-1}$ and $166 \mathrm{~min}^{-1}$, respectively.

(3) Microstructures and chemical composition of the manganese ore pellets vary greatly at $550{ }^{\circ} \mathrm{C}$ with different sintering times. The microstructure of the ore particles is glossy firstly, rough secondly and then cracks forming. The chemical composition change of the ore is the increase of carbon content and decrease of oxygen content, indicating that reduction reaction happens from the surface to the core.

\section{Acknowledgement}

This work was financially supported by the National Natural Science Foundation of China (No. 50874067).

\section{REFERENCES}

[1] J. Yang and Z.M. Zeng, China Manganese Ind. 29 (2) (2011) 6 (in Chinese).

[2] N. Duan, Z.G. Dan and D.N. Song, J. Environ. Eng. Technol. 1 (1) (2011) 75 (in Chinese).

[3] D.W. Hu and D.D. Feng, China Mining Mag. 20 (6) (2011) 1 (in Chinese).

[4] K.S.A. Halim, M. Bahgat, M.B. Morsi and K. ElBarawy, Ironmaking Steelmaking 38 (4) (2011) 279.

[5] A.A. Ismail, E.A. Ali, I.A. Ibrahim and M.S. Ahmed, Can. J. Chem. Eng. 82 (2004) 1296.

[6] C. Abbruzzese, Hydrometallurgy 25 (1990) 85.

[7] T.A. Lasheen, M.N. El Hazek and A.S. Helal, Hydrometallurgy 98(2009) 314.

[8] G. Senanayake, Hydrometallurgy 73 (2004) 215.

[9] R.N. Sahoo, P.K. Naik and S.C. Das, Hydrometallurgy 62 (2001) 157.

[10] S. Acharya, Metall. Trans. B 22 (1991) 259.

[11] M.S. Bafghi, A. Zakeri, Z. Ghasemi and M. Adeli, Hydrometallurgy 90 (2008) 207.

[12] I. De Michelis, F. Ferella, F. Beolchini and F. Vegliò, Waste. Manage. 29 (2009) 128.

[13] D. Hariprasad, B. Dash, M.K. Ghosh and S. Anand, Miner. Eng. 20 (2007) 1293.

[14] Z. Cheng, G.C. Zhu and Y.N. Zhao, Hydrometallurgy 96 (2009) 176.

[15] J.J. Song, G.C. Zhu, P. Zhang and Y.N. Zhao, Acta. Metall. Sin. (Engl. Lett.) 23 (2010) 223.

[16] Y.N. Zhao, G.C. Zhu and Z. Cheng, Hydrometallurgy 105 (2010) 96.

[17] F.W.Y. Momade and Z.G. Momade, Hydrometallurgy 54 (1999) 25.

[18] F. Alenazey, C.G. Cooper, C.B. Dave, S.S.E.H. Elnashaie, A.A. Susu and A.A. Adesina, Catal. Commun. 10 (2009) 406. 